\title{
Human cognitive flexibility depends on dopamine D2 receptor signaling
}

\author{
Mieke van Holstein • Esther Aarts • Marieke E. van der Schaaf • Dirk E. M. Geurts • \\ Robbert J. Verkes • Barbara Franke • Martine R. van Schouwenburg • Roshan Cools
}

Received: 12 January 2011 / Accepted: 4 May 2011 /Published online: 25 May 2011

(C) The Author(s) 2011. This article is published with open access at SpringerLink.com

\begin{abstract}
Rationale Accumulating evidence indicates that the cognitive effects of dopamine depend on the subtype of dopamine receptor that is activated. In particular, recent work with animals as well as current theorizing has

Mieke van Holstein and Esther Aarts contributed equally to this work.

Electronic supplementary material The online version of this article (doi:10.1007/s00213-011-2340-2) contains supplementary material, which is available to authorized users.
\end{abstract}

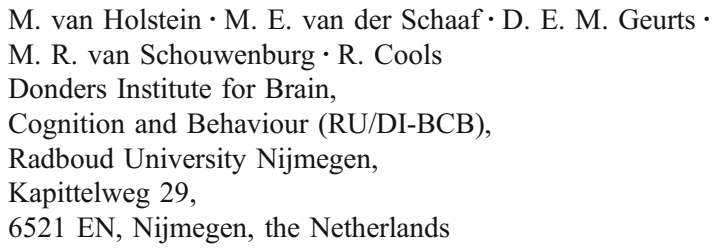

M. E. van der Schaaf - D. E. M. Geurts • R. J. Verkes • B. Franke •

M. R. van Schouwenburg $\cdot$ R. Cools

Department of Psychiatry, Donders Institute for Brain, Cognition and Behavior,

Radboud University Nijmegen Medical Centre,

Reinier Postlaan 10,

6525 GC, Nijmegen, the Netherlands

\section{B. Franke}

Department of Human Genetics,

Radboud University Nijmegen Medical Centre,

Geert Grooteplein-Zuid 10,

6526 GA, Nijmegen, the Netherlands

E. Aarts

Helen Wills Neuroscience Institute, University of California,

Berkeley, CA 94720, USA

\section{M. van Holstein $(\varangle)$}

Donders Centre for Cognitive Neuroimaging,

Radboud University Nijmegen,

P.O. Box 9101, $6500 \mathrm{HB}$, Nijmegen, the Netherlands

e-mail: m.vanholstein@donders.ru.nl suggested that cognitive flexibility depends on dopamine D2 receptor signaling. However, there is no evidence for similar mechanisms in humans.

Objectives We aim to demonstrate that optimal dopamine D2 receptor signaling is critical for human cognitive flexibility.

Methods To this end, a pharmacological pretreatment design was employed. This enabled us to investigate whether effects of the dopamine receptor agonist bromocriptine on task-set switching were abolished by pretreatment with the D2 receptor antagonist sulpiride. To account for individual (genetic) differences in baseline levels of dopamine, we made use of a common variable number of tandem repeat (VNTR) polymorphism in the 3'-untranslated region of the dopamine transporter gene, DAT1.

Results Bromocriptine improved cognitive flexibility relative to placebo, but only in subjects with genetically determined low levels of dopamine $(n=27)$. This beneficial effect of bromocriptine on cognitive flexibility was blocked by pretreatment with the selective dopamine D2 receptor antagonist sulpiride $(n=14)$.

Conclusions These results provide strong evidence in favor of the hypothesis that human cognitive flexibility implicates dopamine D2 receptor signaling.

Keywords DAT1 - SLC6A3 - Striatum · Set switching · Bromocriptine $\cdot$ Sulpiride $\cdot$ Cognitive flexibility

\section{Introduction}

Adequate adaptation to our environment requires a range of behavioral control processes, such as reinforcement learning, incentive motivation, working memory, and set switching. Brain dopamine has been most commonly implicated in 
working memory (Cools 1980; Lyon and Robbins 1975; Oades 1985) and in reward-related processes, including reinforcement learning and incentive motivation (Baldo and Kelley 2007; Berridge and Robinson 1998; Daw et al. 2005; Schultz 2002). However, there is considerable evidence that dopamine is also critical for other control processes, such as set switching. This evidence comes mainly from work with experimental animals (Cools 1980; Floresco et al. 2006; Haluk and Floresco 2009; for a review, see Floresco and Magyar 2006; Oades 1985; Redgrave et al. 1999), drug administration and candidate gene studies in healthy volunteers (Cools et al. 2007b; Mehta et al. 1999; Stelzel et al. 2010) as well as medication withdrawal studies in patients with Parkinson's disease (Cools et al. 2001a, b, 2003).

Accumulating evidence indicates that these cognitive effects of dopamine depend on the subtype of dopamine receptor that is activated (Frank and Fossella 2011; Frank and O'Reilly 2006; Seamans and Yang 2004). In particular, recent in vivo work with animals (Floresco and Jentsch 2011; Floresco et al. 2006) as well as in vitro and theoretical work (Bilder et al. 2004; Durstewitz and Seamans 2008) implicates the dopamine D2 receptor family in set switching. For example, in rodents, blockade of dopamine D2 receptors in the prefrontal cortex (PFC) impaired set shifting, while leaving unaltered performance on working memory tasks (Floresco et al. 2006). According to the dual-state theory put forward recently by Durstewitz and Seamans (2008) and Seamans and Yang (2004), PFC networks can be either in a D1-dominated state, which is characterized by a high energy barrier favoring robust stabilization of representations, or in a D2-dominated state, which is characterized by a low energy barrier favoring fast flexible switching between representations. Consistent with this proposal are findings that dopamine D2 receptor agonists act in opposite ways to dopamine D1 receptor agonists, at least in vitro, on NDMA and GABA currents, neuronal excitability as well as on cyclic AMP production (Durstewitz and Seamans 2008) with dopamine D2 receptor stimulation inducing reduction in NMDA currents and GABAergic inhibition.

The hypothesis that dopamine D2 receptor stimulation is important for set switching is corroborated by findings in humans that the dopamine D2 receptor antagonist sulpiride impaired performance on task-set switching (Mehta et al. 2004). However, according to current standards in animal pharmacology (Feldman et al. 1997), more direct claims about the receptor mechanisms of drug effects can be made based only on the observation that the action of a receptor agonist is blocked by pretreatment with a receptor antagonist, an approach that has been rarely adopted in human research. Here, we provide stronger evidence for a role of dopamine D2 receptor action in cognitive flexibility by adopting such a pretreatment design in young healthy volunteers. Specifically, we demonstrate that an effect of the dopamine receptor agonist bromocriptine on cognitive flexibility was abolished by pretreatment with the dopamine D2 receptor antagonist sulpiride.

Cognitive flexibility was assessed using the task-set switching paradigm (Rogers and Monsell 1995). Unlike traditional measures of cognitive flexibility, such as the Wisconsin Card Sorting Test (Grant and Berg 1948) or indeed any other set switching paradigm with a rule learning component, this paradigm minimizes demands for learning and working memory. It requires the ability to switch rapidly, based on external cues, between already well-established task sets (stimulus-response mappings). Adequate performance does not depend on feedback or trial-and-error learning, and the acquisition of task sets is a rapid learning process, where the formation of associations between stimuli (i.e., the word "left") and responses (i.e., a left button press) does not require extensive training. After the acquisition of task sets in practice blocks, switches can be rapidly performed and measured under time pressure. Moreover, task-set switches are externally cued, which reduces the load on working memory. Therefore, the taskset switching paradigm is relatively specific for measuring set switching.

One challenge to dopaminergic drug research is that there is large variability across different individuals, with only some people benefiting from the drug, thus obviating an effect across the population as a whole (Cools and D'Esposito 2011; Cools and Robbins 2004). We know that at least some of this variability reflects variation in baseline levels of dopamine (Cohen et al. 2007; Cools et al. 2009; Mattay et al. 2003). For example, high-impulsive subjects (who likely exhibit low baseline dopamine function (Buckholtz et al. 2010; Dalley et al. 2007)) are more sensitive to the beneficial effect of dopaminergic drugs on set switching and reversal learning than are low-impulsive subjects (Cools et al. 2007b). Moreover, dopaminergic drugs like bromocriptine, amphetamine, and methylphenidate have diametrically opposite, beneficial, and detrimental effects in subjects with low and high working memory capacity, respectively (e.g. Mattay et al. 2000). The hypothesis that this individual variability reflects variation in baseline levels of dopamine was strengthened by three recent observations. First, working memory capacity correlates positively with dopamine synthesis capacity in the striatum, as measured with neurochemical positron emission tomography (Cools et al. 2008). Second, dopaminergic drug administration was shown to have opposite effects in individuals with high- and low-dopamine synthesis capacity (Cools et al. 2009). Finally, dopaminergic drug administration was shown to have opposite effects as a function of individual genetic variation in dopamine transmission (Cohen et al. 2007; Mattay et al. 2003). Based on these 
observations, we predicted that the dopamine receptor agonist bromocriptine would improve set switching, but only in those individuals with low baseline levels of dopamine.

One way to assess differences in baseline levels of dopamine is by taking into account individual genetic differences. For example, using the same task-set switching paradigm, we previously showed that performance and task-related striatal BOLD responses depended on individual variability in the dopamine transporter (DAT) gene, which has been associated with differences in gene expression in the striatum (Fuke et al. 2001; e.g., Heinz et al. 2000; Mill et al. 2002; VanNess et al. 2005; but see van Dyck et al. 2005). Moreover, these effects were independent of the catechol- $O$-methyltransferase gene (Aarts et al. 2010), which codes for the enzyme that degrades DA primarily in the PFC. Therefore, we took into account individual differences in baseline dopamine function by making use of a common VNTR polymorphism in the 3'-untranslated region of the DAT gene (DAT1/SLC6A3).

We anticipated that subjects with genetically determined lower levels of dopamine as measured with the DATI genotype would show the greatest effect of bromocriptine on set switching. Finally, we predicted that an effect of bromocriptine would be blocked by pretreatment with the selective dopamine D2 receptor antagonist sulpiride.

\section{Materials and methods}

\section{Subjects}

Fifty-five subjects were recruited through advertisements on the campus. DAT1 genotype was available for 49 subjects, and one subject was excluded because of an ADHD diagnosis. The resulting 48 subjects were righthanded, speaking Dutch fluently and European Caucasians (24 males and 24 females, mean age 21.58 years, range 18 27). They were compensated for participation and gave written informed consent in a manner approved by the local ethics committee on research involving human subjects.

\section{Screening and inclusion}

All subjects were screened before inclusion by a medical doctor and a research nurse; this included the MiniInternational Neuropsychiatric Interview (Sheehan et al. 1998) and a physical examination for weight, heart rate, blood pressure, and an electrocardiogram, to exclude major psychiatric, neurological, or medical illness including substance abuse at the time of testing. One subject had a history of anorexia nervosa but was treated successfully 3 years prior to this study and was therefore not excluded.
General procedure

Subjects were asked to abstain from alcohol and nicotine $24 \mathrm{~h}$ before testing and from caffeine on the day of testing. All subjects consumed a light breakfast before ingestion of the drugs. At the start of each session, subjects were asked about their current medical status and their compliance with the above mentioned restrictions.

\section{Experimental design}

Subjects performed a pre-cued task-set switching paradigm (Fig. 1) with a reward manipulation. The task is described extensively elsewhere (Aarts et al. 2010).

Subjects had to respond to incongruent arrow-word combinations, either by responding to the direction of the arrow or the direction indicated by the word ("left" or "right"). As in previous work (Aarts et al. 2010), we included only incongruent trials because the switch cost is largest in the presence of response conflict, which is evoked more by incongruent than congruent targets (Aarts et al. 2009). Before each trial, a task cue appeared indicating according to which task (arrow or word) the subject had to respond. Compared with the previous trial, the task either changed unpredictably (from arrow to word or vice versa; switch trial), or remained the same (repeat trial). The critical measure of interest, the switch cost, was calculated by subtracting performance [error rate (percent) and response time (milliseconds)] on repeat trials from that on switch trials.

Given our prior observation that effects of individual variability in striatal dopamine on set switching are potentiated under conditions of high incentive motivation (Aarts et al. 2010; see also Baldo and Kelley 2007), we also manipulated reward anticipation by presenting high and low reward cues prior to the task cue. The reward cue informed the subjects whether 1 cent (low reward) or 10 cents (high reward) could be earned with a correct and quick response. Immediately following the response, feedback was given (e.g., "correct! 10 cents"). There was a variable interval between the reward cue and the task cue of 1 to $2 \mathrm{~s}$. Subjects responded with their index fingers on a left or right button box.

The main experiment consisted of 160 trials and lasted $\sim 30$ min with a 30 -s break after every 32 trials. In the break, the amount of money the subject earned thus far was displayed on the screen, and subjects were told in advance the total amount would be added to their financial compensation as a bonus.

Pharmacological procedure

All 48 subjects were tested at least twice: once after an oral dose of the dopamine receptor agonist bromocriptine 
Fig. 1 Example trials from the experimental paradigm. In the first trial, the reward cue indicated that the subject could earn 1 cent with a correct and sufficiently quick response (as opposed to 10 cents in the second trial). The task cue indicated that the subject should respond to the arrow of the incongruent arrow-word Stroop-like target in the first trial, but to the word of the incongruent arrow-word Stroop-like target in the second trial. Hence, the second trial is an example of a switch of the task relative to the previous trial

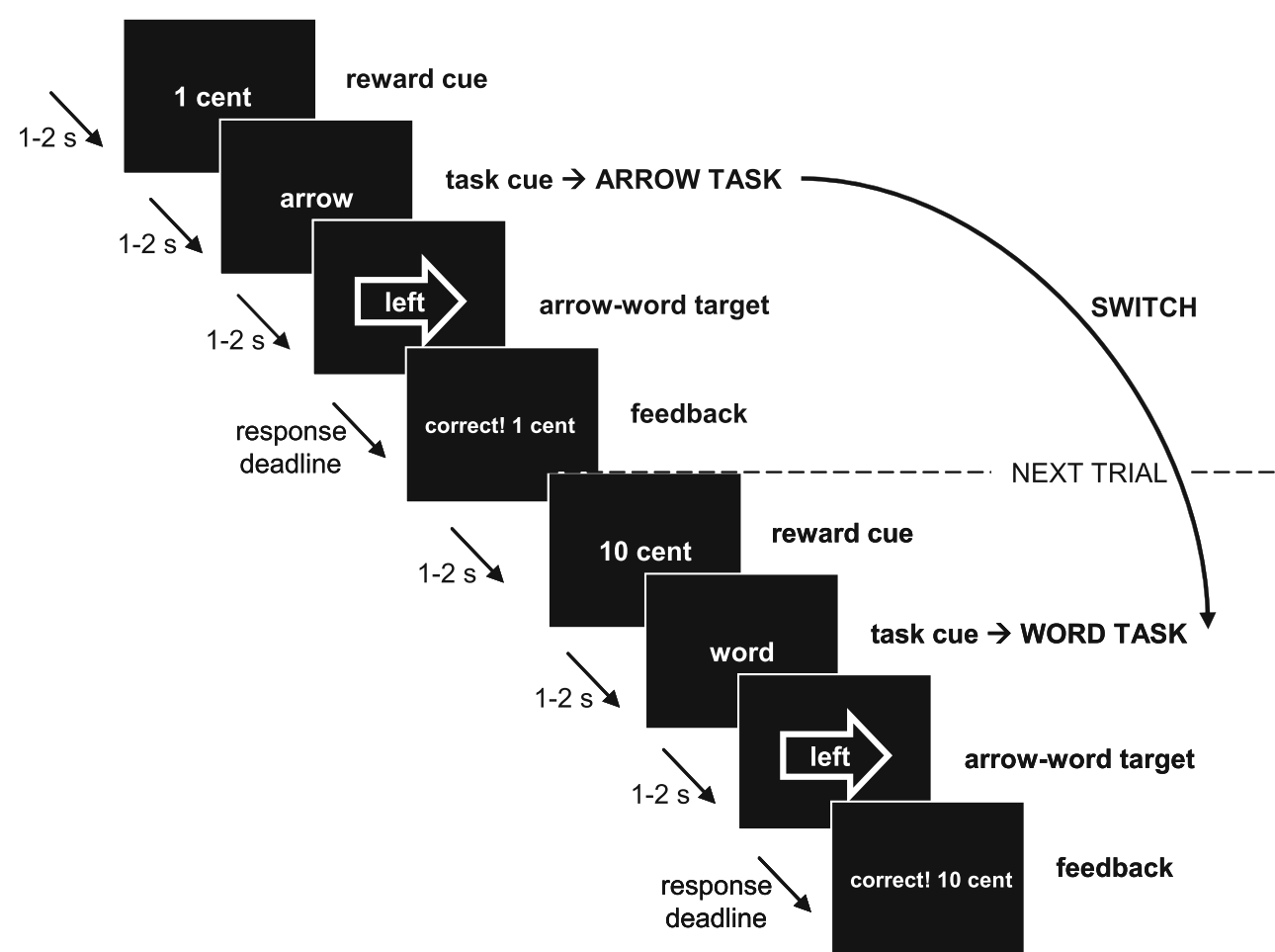

(Parlodel ${ }^{\circledR}$, Novartis; $1.25 \mathrm{mg}$ ) and once after a placebo. In addition, a subgroup $(n=14)$ received placebo or bromocriptine after pretreatment with placebo or the dopamine D2 receptor antagonist sulpiride (Dogmatil ${ }^{\circledR}$, Sanofi-Aventis; $400 \mathrm{mg}$ ) on two other occasions. The order of administration of the two or four sessions was randomized according to a double-blind, placebo-controlled crossover design. The sessions were always separated by at least 1 week. The doses described here have been used before in similar psychopharmacological studies and have been shown to be well tolerated by subjects (Cools et al. 2007b; Mehta et al. 2004). Sulpiride or placebo was administered 30 min prior to bromocriptine or placebo.

The task was performed $\sim 4 \mathrm{~h}$ after sulpiride or placebo intake and $\sim 3.5 \mathrm{~h}$ after bromocriptine or placebo intake. Time of dosing was optimized for detecting drug effects during functional magnetic resonance imaging (fMRI) that took place immediately prior to the experiment reported here (data to be published elsewhere). The timing of the fMRI sessions was based on prior studies showing behavioral effects at similar doses and at similar time points in healthy volunteers (Cools et al. 2007b; Gibbs and D’Esposito 2005a, b; Kimberg et al. 1997; Luciana and Collins 1997; Luciana et al. 1992; Mehta et al. 2003, 2004, 2008, 2001). Mean time to maximal plasma concentration of sulpiride is about $3 \mathrm{~h}$, with a plasma half-life of about $12 \mathrm{~h}$ (Mehta et al. 2003), while mean time to maximal plasma concentration of bromocriptine is about $2.5 \mathrm{~h}$ with a plasma half-life of about $7 \mathrm{~h}$ (Deleu et al. 2002). The combination of plasma kinetics and physiological effects shows that the time of testing coincided with high plasma concentrations of both bromocriptine and sulpiride (Supplementary results: Table $\mathrm{S} 1$ ).

A session started either at 8:00, 8:30, or 10:30 AM, and starting time was kept identical between each subject's two or four sessions. Blood pressure, heart rate, mood measures [visual analog scales; 16 ratings on a scale of 0-100 (Bond and Lader 1974)] and blood samples $(6 \mathrm{ml})$ were taken immediately after arrival of the subject and on average 73.1 (SD 45.4) min before the task was performed. Blood samples were used to determine the change in prolactin levels due to dopamine D2 receptor binding (Fitzgerald and Dinan 2008; Supplementary material and methods).

\section{Neuropsychological assessment}

On the day of screening, subjects completed a number of questionnaires, including the Beck Depression Inventory (BDI; Beck et al. 1961), Barratt Impulsiveness Scale (BIS-11; Patton et al. 1995), State-Trait Anxiety Inventory (STAI; Spielberger et al. 1970), and Listening span (Salthouse et al. 1991; Supplementary material and methods). Verbal IQ was determined using Dutch Adult Reading Test, the Dutch version of the National Adult Reading Test (Schmand et al. 1991). 
Genotyping

All molecular genetic analyses were carried out in a CCKL-certified laboratory at the department of Human Genetics of the Radboud University Nijmegen Medical Centre. DNA was isolated from saliva samples using Oragene kits (DNA Genotek Inc, Ottawa, ON, Canada). Genotyping of the 40-bp VNTR polymorphism in the $3^{\prime}$ untranslated region of the SLC6A3/DAT1 gene encoding the DAT was performed as follows: Genomic DNA (100 ng) was amplified with $0.2 \mu \mathrm{M}$ fluorescently labeled forward primer (5'-Ned-TGTGGTGTAGGGACGGCCTGAGAG-3') and $0.2 \mu \mathrm{M}$ reverse primer $\left(5^{\prime}\right.$-CTTCCTGGAGGT CACGGCTCAAGG-3') with PIG tail, $0.25 \mathrm{mM}$ dNTPs, 0.4 U AmpliTaq Gold DNA polymerase (Applied Biosystems, Nieuwerkerk a/d IJssel, the Netherlands) in an PCR Optimized buffer D (Invitrogen, Breda, the Netherlands), containing $10 \%$ DMSO $(v / v)$. Cycling conditions were $12 \min 95^{\circ} \mathrm{C}$ followed by 35 cycles of $1 \min 94^{\circ} \mathrm{C}, 1 \mathrm{~min}$ $58^{\circ} \mathrm{C}$, and $1 \mathrm{~min} 72^{\circ} \mathrm{C}$ and a final $5 \mathrm{~min}$ at $72^{\circ} \mathrm{C}$. PCR products were diluted 10 times, and $1 \mu \mathrm{l}$ of the diluted PCR product together with $9.7 \mu \mathrm{l}$ formamide and $0.3 \mu \mathrm{l}$ GeneScan-600 Liz Size Standard ${ }^{\mathrm{TM}}$ (Applied Biosystems) was analyzed on a 3730 Genetic Analyzer (Applied Biosystems) according to the protocol of the manufacturer. Analysis of the length of the PCR products was performed with Genemapper software. To investigate the random genotyping error rate, the lab included 5\% duplicate DNA samples, which had to be $100 \%$ consistent. In addition, $4 \%$ blanks were included, which were required to be negative.

Most of the participants (except three) took part in the study before their genotype was determined. After participation, three groups of genotypes were established: a group homozygous for the common 10 -repeat allele $(10 \mathrm{R} / 10 \mathrm{R} ; n=27$, mean age $21.7 \pm 2.2,12$ females), a group homozygous for the nine-repeat allele (9R/9R; $n=7)$, and a group of $9 \mathrm{R} / 10 \mathrm{R}$ heterozygotes $(n=14)$. The $9 \mathrm{R} / 9 \mathrm{R}$ and $9 \mathrm{R} / 10 \mathrm{R}$ subjects were combined into one group of $9 \mathrm{R}$ carriers $(n=21$, mean age $21.4 \pm 1.9,12$ females). Three 10R homozygotes of this sample were selected from an existing genetic database at the center. Of the subgroup of participants who received four instead of two drug sessions, we only included data from the 10R homozygotes ( $n=14$; mean age $21.9 \pm 2.4$, six females) because these were the participants showing an effect of bromocriptine in the larger sample.

The DAT removes dopamine from the synapse into the presynaptic neuron (Willeit and Praschak-Rieder 2010), thereby terminating its action. The 10-repeat allele has been associated with increased gene expression and presumably lower levels of synaptic dopamine in the striatum relative to the nine-repeat allele (Fuke et al. 2001; e.g., Heinz et al. 2000; Mill et al. 2002; VanNess et al. 2005; but see van Dyck et al. 2005).
Statistical analyses

The mean latencies of the correct responses and the proportion of errors were analyzed using a repeatedmeasures general linear model with the within-subjects factors Reward, Switching, and Drug and the betweensubjects factor DAT1 genotype group. A similar ANOVA with Order (of drug administration: the order of bromocriptine and placebo in the large sample, or the order of all four drug sessions in the subgroup) as a covariate of no interest revealed no relevant interaction effects with Order (i.e., Order $\times$ Drug $\times$ Switching: $F(1,25)<1 ; F(1,12)<1)$ for any of the reported Drug $\times$ Switching interactions. Accordingly, the ANOVA was run without this additional factor. Effects of sulpiride (pre)treatment were assessed for the group that showed an effect of bromocriptine (i.e., the $10 \mathrm{R}$ homozygotes). The first trial of each block was eliminated from analyses as they were neither switch nor repeat trials (five trials per subject).

To investigate whether drug effects reflected a form of learning rather than set switching, we also assessed learning curves for each subject, i.e., switch costs as a function of time (Supplementary results: learning effect). This supplementary analysis revealed that the drug effects did not vary as a function of time.

Prolactin and mood ratings (three factors: contentedness, alertness, and calmness, according to Bond and Lader (1974)) were available for 46 subjects. For each session, we calculated the drug-induced change in prolactin and mood ratings (after-before drug intake) and compared this with the placebo-induced change [difference score $=($ drug session (Time2-Time1))-(placebo session (Time2-Time1))]. Pearson correlations were calculated, in the 10R homozygotes, between trait anxiety (STAI), trait impulsivity (BIS-11), depression (BDI), listening span scores, bromocriptineinduced mood changes, bromocriptine-induced prolactin changes, and bromocriptine-induced changes in set switching.

\section{Results}

Genetic variation predicts the effect of bromocriptine on set switching

All 48 subjects performed the pre-cued task-set switching paradigm after receiving a placebo or the dopamine receptor agonist bromocriptine $(1.25 \mathrm{mg})$. Under placebo, there was no difference in terms of set switching between the DAT1 genotype groups [error rates; Switching $\times D A T 1$ : $F(1,46)<1]$. However, consistent with our prediction, bromocriptine improved set switching: The proportion of errors on switch trials relative to repeat trials (i.e., the error 
switch cost) was reduced after bromocriptine relative to placebo in subjects with genetically determined low striatal dopamine levels (i.e., the DAT1 10R homozygotes; $n=27$ ) [Drug $\times$ Switching: $F(1,26)=5.4, p=0.028$ ]. This effect was driven by a combination of improvement on switch trials and impairment on repeat trials (Supplementary results: Table S2b). By contrast, there was no effect of bromocriptine on set switching in the DAT1 9R carriers $(n=21)$, who presumably have higher levels of striatal dopamine [Drug $\times$ Switching: $F(1,20)<1]$ (Fig. 2; Supplementary results: Table S2a) [Drug $\times$ Switching $\times$ DAT1: $F(1,46)=1.8, p>$ 0.1 . None of these effects were found in terms of response times (all $p>0.2$; Supplementary results: Table $\mathbf{S} 2 \mathrm{a}$; $\mathbf{S} 2 \mathrm{~b}$; Supplementary discussion).

Effect of bromocriptine on set switching is blocked by sulpiride pretreatment

To investigate whether the beneficial effect of bromocriptine on set switching in the 10R homozygotes was mediated by stimulation of dopamine D2 receptors, we assessed the effect of bromocriptine after blocking the dopamine D2 receptors with sulpiride $(400 \mathrm{mg}$ ) in a subgroup of the $10 \mathrm{R}$ homozygotes $(n=14)$. First we tested whether the reduced switch cost after bromocriptine administration was still present in this smaller group. Again, we found that bromocriptine reduced the error switch cost relative to placebo [Drug $\times$ Switching: $F(1,13)=5.6, p=0.034]$, an effect that again reflected a combination of improved

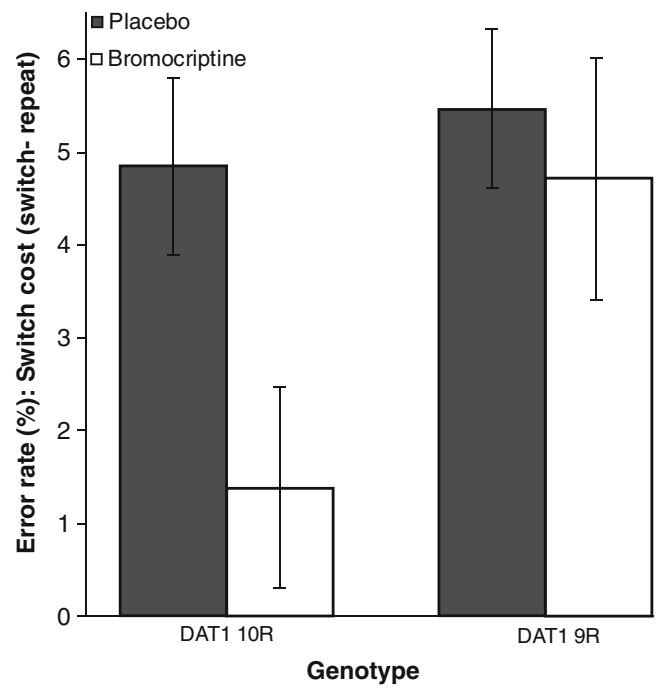

Fig. 2 Bromocriptine improved set switching in 10R homozygotes. The switch cost (switch-repeat) in terms of error rate (percent) differed between the two genotype groups: Bromocriptine reduced the switch costs in the $10 \mathrm{R}$ homozygotes $(n=27$; with relatively lower levels of striatal dopamine), but not in the $9 \mathrm{R}$ carriers $(n=21)$. These results indicate that the effect of bromocriptine on set switching depends on baseline levels of striatal dopamine. Error bars represent the standard error of the difference between switch and repeat trials switching and impaired repeat performance (Supplementary results: Table S2c). As anticipated, blocking the dopamine D2 receptors by pretreatment with sulpiride abolished the effect of bromocriptine relative to placebo [Drug $\times$ Switching: $F$ $(1,13)<1]$. Sulpiride by itself, relative to placebo, had no effect on set switching $[F(1,13)<1]$ (Fig. 3; Supplementary results: Table S2c and Fig. S2) [Bromocriptine (on/off) $\times$ Sulpiride (on/off) $\times$ Switching: $F(1,13)=3, p=0.1]$. None of these effects was present in the response times (all $p>0.3$; Supplementary results: Table S2c; Supplementary discussion).

Effects of motivation on set switching vary as a function of genetic variation, but are not modulated by bromocriptine

Our previous study (Aarts et al. 2010) revealed beneficial effects of incentive motivation on set switching. Specifically, switch costs were reduced when subjects anticipated high reward, relative to when they anticipated low reward. However, this effect was restricted to subjects with genetically determined high levels of striatal dopamine (i.e., the 9R carriers). Here we replicate this effect in an independent sample: irrespective of drug, set switching varied as a function of anticipated reward and DATI genotype. The 9R carriers showed a larger response time benefit of anticipated reward on switching than did the 10R homozygotes (Supplementary results: Fig. S1 and Supplementary discussion) [Reward $\times$ Switching $\times D A T 1: F(1,46)=5.3, p=0.026]$.

However, contrary to our expectations, we observed no difference in terms of this effect between the bromocriptine and placebo session [Reward $\times$ Switching $\times D A T 1 \times$ Drug: $F(1$, 46) $=1.5, p>0.1][$ Reward $\times$ Switching $\times$ Drug: $F(1,46)<1]$. The degree to which reward affected performance irrespective of set switching [main effect Reward: response time: $F$ $(1,46)=19.4, p<0.001$; error rate: $F(1,46)=20.6, p<0.001]$ was also not modulated by bromocriptine [error rate and response time: Reward $\times$ Drug: $F(1,46)<1]$ [Reward $\times$ Drug $\times$ DAT1: $F(1,46)=1.6, p>0.2]$.

Neuropsychological assessments

There were no differences between the two DATl genotype groups in term of age, gender, IQ, trait impulsivity (BIS11), depression (BDI), trait anxiety (STAI), or working memory capacity (listening span; all $p>0.2$; Supplementary results: Table S3a), and there were no significant correlations between any of these trait measures and drug-induced changes in performance (all $p>0.2$ ).

Listening span

Working memory capacity (measured with listening span (Daneman and Carpenter 1980; Salthouse et al. 1991)) has 


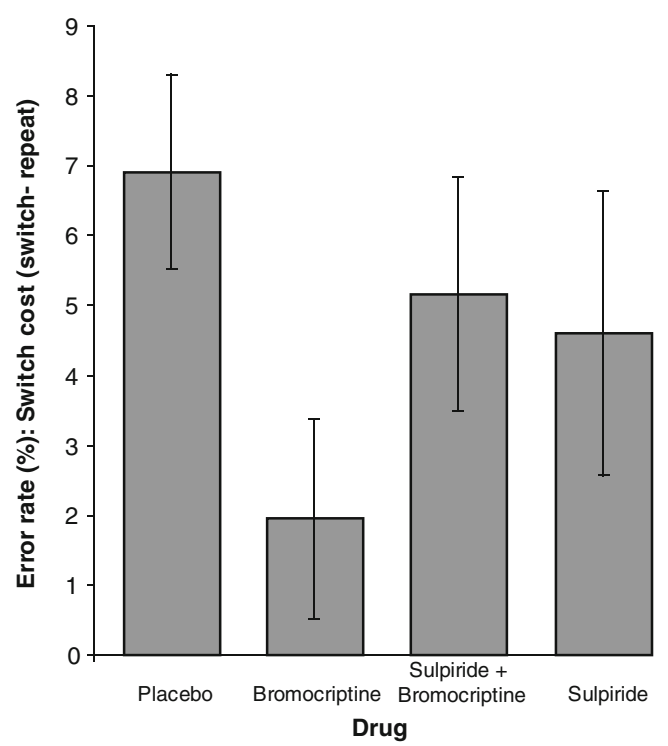

Fig. 3 Sulpiride abolished the effect of bromocriptine. Shown is the switch cost (switch-repeat) in error rate (percent) for the $10 \mathrm{R}$ homozygotes $(n=14)$ who received pretreatment with sulpiride, as well as bromocriptine and sulpiride alone. In this smaller group, bromocriptine also reduced the switch cost relative to placebo. However, when the same subjects received sulpiride pretreatment, bromocriptine no longer facilitated set switching. Error bars represent the standard error of the difference between switch and repeat trials

been associated with striatal dopamine synthesis capacity (Cools et al. 2008). Moreover, previous studies have shown that dopaminergic drug effects can be predicted from working memory capacity (Cools et al. 2007b; Frank and O'Reilly 2006; Gibbs and D'Esposito 2005b; Kimberg et al. 1997). Accordingly, we assessed drug effects as a function of listening span. To this end, we divided the group into low-span participants $(n=23)$ and high-span participants $(n=25)$, using a median-split analysis (Supplemental Table S3b). Consistent with prior work and like the 10R DAT1 genotype group, the low-span group was sensitive to the beneficial effects of bromocriptine on set switching [Drug $\times$ Switching: $F(1,22)=4.457, p=0.046$ ] Conversely, the high-span group was not sensitive to the effect of bromocriptine [Drug $\times$ Switching: $F(1,24)<1$ ], similar to the DAT1 9R group [Drug $\times$ Switching $\times$ Span: $F$ $(1,46)=1.2, p>0.2]$. Moreover, in the subgroup of lowspan participants that took part in all four drug sessions, bromocriptine also reduced the switch cost [Drug $\times$ Switching $F(1,9)=5.466, p=0.044]$, an effect that was not present after pretreatment with sulpiride [Drug $\times$ Switching: $F(1,9)$ $<1]$ nor after sulpiride alone $[F(1,9)=1.1, p=0.33]$.

Effects of drugs on mood ratings and prolactin levels

Participants reported no drug-induced changes in mood in the large sample (all $p>0.3$ ) or in the subgroup (all $p>$
0.05). There were also no significant correlations between drug-induced changes in task performance and druginduced changes in mood (all $p>0.3$ ).

Furthermore, bromocriptine decreased plasma prolactin levels relative to placebo, whereas sulpiride increased plasma prolactin levels relative to placebo (Supplementary results: Table S1). These data evidence the opposite effects of the two drugs in vivo. The finding that the prolactin response was not nullified in the combined sulpiride and bromocriptine session (sulpiride versus sulpiride and bromocriptine $t(21)=-0.279)$ likely reflects the fact that sulpiride was administered prior to bromocriptine. The effect of sulpiride was disproportionately large, thus masking any subsequent effect of bromocriptine.

\section{Discussion}

The present results show that the dopamine receptor agonist bromocriptine improved set switching by stimulating dopamine D2 receptors. Specifically, bromocriptine reduced the error switch cost in individuals with genetically determined low dopamine levels, and this beneficial effect of bromocriptine on set switching was abolished by pretreatment with the selective dopamine D2 receptor antagonist sulpiride. This finding significantly strengthens prior evidence (Cools et al. 2007b; Durstewitz and Seamans 2008; Floresco et al. 2006; Mehta et al. 2004; Stelzel et al. 2010) for a role of dopamine D2 receptor signaling in set switching, thus further establishing a role for dopamine outside the domains of working memory and learning in humans. In particular, the data concur with the dual-state theory put forward recently by Durstewitz and Seamans (2008) and Seamans and Yang (2004), which is grounded in in vitro neurophysiology and biophysically realistic computational modeling work (see Introduction). According to this theory, dopamine D2 receptor stimulation favors fast flexible switching between different task-relevant representations, by allowing multiple inputs to impinge simultaneously on the PFC. It also fits with data from animal studies showing that genetic overexpression of striatal dopamine D2 receptors (Kellendonk et al. 2006) and abnormal increases in dopamine D2 receptor activity in the rodent striatum alters set shifting in rodents (Haluk and Floresco 2009).

It might be noted that the present finding of a blockade of the beneficial effect of bromocriptine on set switching by pretreatment with sulpiride highlights the role of dopamine D2 receptor signaling in set switching, but does not directly rule out the involvement of dopamine D1 receptor signaling or the importance of synergistic action between dopamine D1 and D2 receptor signaling in set switching. Indeed rodent work suggests that both dopamine D1 and D2 receptor signaling are important for cognitive flexibility 
(Floresco et al. 2006). The conclusion that set switching implicates dopamine D2, but not D1 receptor signaling would require demonstration that effects of bromocriptine were not blocked by a dopamine D1 receptor antagonist. Unfortunately, there is a relative lack of dopamine D1 selective drugs available for human research, and accordingly, such a demonstration will have to await future developments.

An interesting feature of current dual-state theory is that the beneficial effect of dopamine D2 receptor stimulation on set switching might be accompanied by a detrimental effect on the stabilization of current task-relevant representations. This hypothesis is corroborated here by the observation (as well as our prior observation; Cools et al. 2007b) that the drug effect on the switch cost was driven by a combination of better performance on switch trials and poorer performance on repeat trials (Supplementary results: Table S2). Indeed performance on repeat trials would suffer from poor stabilization of task-relevant representations. It also concurs with previous findings in humans that the dopamine D2 receptor antagonist sulpiride impaired performance on task-set switching but, by contrast, improved performance on a delayed response task that required the stabilization of representations in the face of task-irrelevant distraction (Mehta et al. 2004).

Unlike this prior study (Mehta et al. 2004), we here failed to uncover a significant task-set switching impairment after administration of sulpiride. This is surprising, not only given that prior finding but also given our observation that sulpiride did block the beneficial effect of bromocriptine on set switching. There are a number of possible explanations for this discrepancy. First, there might have been a difference between the two studies in terms of the time of testing after drug intake. Our set switching data were acquired approximately $4 \mathrm{~h}$ after drug intake, while (Mehta et al. 2004) started testing already 90 min after drug intake. Dopamine D2 receptor occupancy after sulpiride administration, measured approximately $2 \mathrm{~h}$ after intake, is relatively modest (Mehta et al. 2008). Accordingly, dopamine D2 receptor occupancy after $4 \mathrm{~h}$ might have been insufficient to exert an effect on its own, even though it was clearly sufficient to block the effects of bromocriptine. A second possibility is that it is particularly difficult to demonstrate impairment using the present version of the task-set switching paradigm, where subjects were constantly encouraged and motivated to perform as well as they could by means of monetary incentive. Thus, the paradigm might simply not have been sensitive to detecting impairment (as opposed to improvement). In any case, there is one major interpretational advantage of our failure to find an impairment after administration of sulpiride by itself; indeed, this feature of the data implies that the effect of bromocriptine was blocked rather than masked (or averaged out) by an effect of sulpiride, thus strengthening our conclusion that dopamine D2 receptor stimulation is essential for bromocriptine to enhance set switching performance.

The baseline-dependent effects of bromocriptine on set switching resemble previously observed effects of bromocriptine on reward learning and working memory (Cools et al. 2007b, 2009). For example, we have previously shown that beneficial effects of bromocriptine on reward learning are greatest in subjects with low dopamine synthesis capacity (Cools et al. 2009). Similarly, we have also shown that beneficial effects of bromocriptine on set switching were restricted to high-impulsive subjects (Cools et al. 2007b), with impulsivity being associated with low baseline dopamine function (Buckholtz et al. 2010; Dalley et al. 2007).

One possible mechanism underlying this enhanced beneficial effect of dopamine receptor stimulation in low dopamine subjects is enhanced postsynaptic receptor function. Indeed the dopamine system is highly plastic and regulates itself to maintain equilibrium, partly through changes in transporter and receptor density/function. The DAT1 10R subjects are thought to be characterized by high dopamine transporter density, which is associated with enhanced uptake of dopamine from the synapse and thus reduced remaining levels of dopamine in the synapse. Following the rules of homeostasis, such low synaptic dopamine levels might well be accompanied by increased postsynaptic dopamine receptor function. Increased postsynaptic receptor function would compensate for the reduced synaptic dopamine levels, thus contributing to the maintenance of equilibrium in overall dopamine function. In other words, enhanced receptor function might represent a self-regulatory or compensatory mechanism aimed at maintaining homeostasis, i.e., optimal functioning of the low dopamine system. In this context, the lack of a DATI effect on set switching at baseline (under placebo) is not surprising because any dopamine-dependent function including set switching should depend on a combination of synaptic dopamine levels and receptor function. Indeed high- and lowdopamine groups have been observed to perform similarly under placebo in a number of previous studies (Cools et al. 2007b; Kimberg et al. 1997). Critically, this enhanced postsynaptic receptor function might underlie the disproportional response of low dopamine subjects to dopamine receptor stimulation. Thus, the significant effect of dopamine receptor stimulation with bromocriptine in the $10 \mathrm{R}$, but not the $9 \mathrm{R}$ group, is not surprising, given these presumed hyperfunctioning dopamine receptors.

Our finding that bromocriptine did not impair subjects with higher baseline levels of dopamine (i.e., the $9 \mathrm{R}$ carriers) was somewhat surprising given prior observations that subjects with already optimized levels of dopamine can be impaired by dopaminergic drug administration (e.g., Cools et al. 2009; although see Cools et al. 2007b). Such detrimental effects of 
dopaminergic drug administration have been accounted for by inverted U-shaped relationships between dopamine receptor stimulation and cognitive performance, whereby both too much as well as too little dopamine leads to poor performance. Our finding that the $9 \mathrm{R}$ carriers were not impaired accordingly might reflect their positioning near, but not quite yet at the optimum of the so-called inverted U-shaped curve (Cools and D'Esposito 2011; Cools and Robbins 2004). However, the obvious alternative hypothesis relates to our failure to obtain an effect of sulpiride; the paradigm might simply not be sensitive to detecting impairment, perhaps due to high levels of incentive motivation induced by the reward cues that preceded each trial. According to this alternative hypothesis, subjects with high basal levels of dopamine will exhibit impairment after bromocriptine on a task that does not involve monetary reward.

Set switching has most often been associated with the PFC (Aron et al. 2004; Derrfuss et al. 2005; Monsell 2003; Sakai 2008), and traditionally, cognitive effects of dopamine are ascribed to modulation of the PFC. However, recent theories as well as empirical data have highlighted a complementary role for (dopamine in) the striatum (Braver and Cohen 2000; Cools et al. 2004; Frank et al. 2001; Leber et al. 2008; Lewis et al. 2004; McNab and Klingberg 2008). Specifically, recent computational work has emphasized the role of dopamine in the striatum in the updating of current task-relevant representations (Hazy et al. 2006). The suggestion that the striatum is well suited to serve the gating mechanism that updates current task-relevant representations in the PFC concords with a rapidly growing body of data from functional neuroimaging and animal studies on working memory (Collins et al. 2000; Dahlin et al. 2008; Dodds et al. 2009; Marklund et al. 2009; $\mathrm{McNab}$ and Klingberg 2008). Furthermore, it also concurs with empirical data from human imaging and animal studies showing (effects of dopamine D2 receptor manipulations on) striatal involvement during set shifting (Aarts et al. 2010; Clatworthy et al. 2009; Collins et al. 1998; Cools et al. 2003, 2007a; Cools and Robbins 2004; Cools et al. 2007b; Dodds et al. 2008; Floresco and Magyar 2006; Haluk and Floresco 2009; Kellendonk et al. 2006; Leber et al. 2008; Lyon and Robbins 1975; Oades 1985; van Schouwenburg et al. 2010). For example, we have recently shown, using dynamic causal modeling of fMRI data, that activity in the striatum may regulate set switching by modulating (or "gating") connectivity between the PFC and task-relevant representations in posterior cortex (van Schouwenburg et al. 2010). Moreover, Stelzel et al. (2010) reported decreased flexibility in subjects with increased dopamine D2 receptor densities, an effect that was accompanied by increased PFC activity and increased PFC-striatal coupling (possibly reflecting decreased neural efficiency). Although both the DAT and dopamine D2 receptors are most abundant in the striatum (Camps et al. 1989; Ciliax et al. 1999; Hurd et al. 2001), the improvement of switching in the current study might well have been a combination of drug-induced changes in striatal and PFC activity; we therefore do not rule out the involvement of the PFC in the present study. However, the finding that effects of bromocriptine are DAT and dopamine D2 dependent strongly implicates the striatum. This observation also concurs with previous work with patients with Huntington's disease (Aron et al. 2003), Parkinson's disease (Cools et al. 2001a, b), and focal basal ganglia lesions (Cools et al. 2006).

In sum, our findings strengthen evidence in favor of the hypothesis that dopamine D2 receptor signaling is important for set switching, with prior evidence suggesting that this effect is mediated by the striatum. The data also illustrate the need to take into account genetic variation in baseline levels of striatal dopamine when predicting drug effects. Finally, although the sample size was rather small, this study emphasizes the value of employing the pretreatment approach in humans and future studies might adopt this approach to enable replication and extension of the present results.

Acknowledgments This study was supported by a Vidi Grant to RC from the Innovational Research Incentives Scheme of the Netherlands Organisation for Scientific Research. We thank the Chemical Endocrinology Department at the Radboud University Nijmegen, especially Fred Sweep and Rob van den Berg, for analyzing the blood samples. We thank Angelien Heister for molecular genetics work.

Open Access This article is distributed under the terms of the Creative Commons Attribution Noncommercial License which permits any noncommercial use, distribution, and reproduction in any medium, provided the original author(s) and source are credited.

\section{References}

Aarts E, Roelofs A, van Turennout M (2009) Attentional control of task and response in lateral and medial frontal cortex: brain activity and reaction time distributions. Neuropsychologia 47:2089-2099

Aarts E, Roelofs A, Franke B, Rijpkema M, Fernandez G, Helmich RC, Cools R (2010) Striatal dopamine mediates the interface between motivational and cognitive control in humans: evidence from genetic imaging. Neuropsychopharmacology 35:1943-1951

Aron AR, Watkins L, Sahakian BJ, Monsell S, Barker RA, Robbins TW (2003) Task-set switching deficits in early-stage Huntington's disease: implications for basal ganglia function. J Cogn Neurosci 15:629-642

Aron AR, Monsell S, Sahakian BJ, Robbins TW (2004) A componential analysis of task-switching deficits associated with lesions of left and right frontal cortex. Brain 127:1561-1573

Baldo BA, Kelley AE (2007) Discrete neurochemical coding of distinguishable motivational processes: insights from nucleus accumbens control of feeding. Psychopharmacology (Berl) 191:439-459

Beck AT, Ward CH, Mendelson M, Mock J, Erbaugh J (1961) An inventory for measuring depression. Arch Gen Psychiatry 4:561-571

Berridge KC, Robinson TE (1998) What is the role of dopamine in reward: hedonic impact, reward learning, or incentive salience? Brain Res Brain Res Rev 28:309-369 
Bilder RM, Volavka J, Lachman HM, Grace AA (2004) The catechol-O-methyltransferase polymorphism: relations to the tonic-phasic dopamine hypothesis and neuropsychiatric phenotypes. Neuropsychopharmacology 29:1943-1961

Bond AJ, Lader MH (1974) The use of analogue scales in rating subjective feelings. Br J Med Psychol 47:211-218

Braver TS, Cohen JD (2000) On the control of control: the role of dopamine in regulating prefrontal function and working memory. In: Monsell S, Driver J (eds) Control of cognitive processes. Attention and performance XVIII. MIT, Cambridge, pp 713-737

Buckholtz JW, Treadway MT, Cowan RL, Woodward ND, Li R, Ansari MS, Baldwin RM, Schwartzman AN, Shelby ES, Smith CE, Kessler RM, Zald DH (2010) Dopaminergic network differences in human impulsivity. Science 329:532

Camps M, Cortes R, Gueye B, Probst A, Palacios JM (1989) Dopamine receptors in human brain: autoradiographic distribution of D2 sites. Neuroscience 28:275-290

Ciliax BJ, Drash GW, Staley JK, Haber S, Mobley CJ, Miller GW, Mufson EJ, Mash DC, Levey AI (1999) Immunocytochemical localization of the dopamine transporter in human brain. J Comp Neurol 409:38-56

Clatworthy PL, Lewis SJ, Brichard L, Hong YT, Izquierdo D, Clark L, Cools R, Aigbirhio FI, Baron JC, Fryer TD, Robbins TW (2009) Dopamine release in dissociable striatal subregions predicts the different effects of oral methylphenidate on reversal learning and spatial working memory. J Neurosci 29:4690-4696

Cohen MX, Krohn-Grimberghe A, Elger CE, Weber B (2007) Dopamine gene predicts the brain's response to dopaminergic drug. Eur J Neurosci 26:3652-3660

Collins P, Roberts AC, Dias R, Everitt BJ, Robbins TW (1998) Perseveration and strategy in a novel spatial self-ordered sequencing task for nonhuman primates: effects of excitotoxic lesions and dopamine depletions of the prefrontal cortex. J Cogn Neurosci 10:332-354

Collins P, Wilkinson LS, Everitt BJ, Robbins TW, Roberts AC (2000) The effect of dopamine depletion from the caudate nucleus of the common marmoset (Callithrix jacchus) on tests of prefrontal cognitive function. Behav Neurosci 114:3-17

Cools AR (1980) Role of the neostriatal dopaminergic activity in sequencing and selecting behavioural strategies: facilitation of processes involved in selecting the best strategy in a stressful situation. Behav Brain Res 1:361-378

Cools R, D'Esposito M (2011) Inverted-U shaped dopamine actions on human working memory and cognitive control. Biol Psychiatry. doi:10.1016/j.biopsych.2011.03.028

Cools R, Robbins TW (2004) Chemistry of the adaptive mind. Philos Trans A Math Phys Eng Sci 362:2871-2888

Cools R, Barker RA, Sahakian BJ, Robbins TW (2001a) Enhanced or impaired cognitive function in Parkinson's disease as a function of dopaminergic medication and task demands. Cereb Cortex 11:1136-1143

Cools R, Barker RA, Sahakian BJ, Robbins TW (2001b) Mechanisms of cognitive set flexibility in Parkinson's disease. Brain 124:2503-2512

Cools R, Barker RA, Sahakian BJ, Robbins TW (2003) L-Dopa medication remediates cognitive inflexibility, but increases impulsivity in patients with Parkinson's disease. Neuropsychologia 41:1431-1441

Cools R, Clark L, Robbins TW (2004) Differential responses in human striatum and prefrontal cortex to changes in object and rule relevance. J Neurosci 24:1129-1135

Cools R, Ivry RB, D'Esposito M (2006) The human striatum is necessary for responding to changes in stimulus relevance. J Cogn Neurosci 18:1973-1983

Cools R, Lewis S, Clark L, Barker R, Robbins TW (2007a) L-DOPA disrupts activity in the nucleus accumbens during reversal learning in Parkinson's disease. Neuropsychopharmacology $32: 180-189$

Cools R, Sheridan M, Jacobs E, D'Esposito M (2007b) Impulsive personality predicts dopamine-dependent changes in frontostriatal activity during component processes of working memory. $\mathrm{J}$ Neurosci 27:5506-5514

Cools R, Gibbs SE, Miyakawa A, Jagust W, D'Esposito M (2008) Working memory capacity predicts dopamine synthesis capacity in the human striatum. J Neurosci 28:1208-1212

Cools R, Frank MJ, Gibbs SE, Miyakawa A, Jagust W, D'Esposito M (2009) Striatal dopamine predicts outcome-specific reversal learning and its sensitivity to dopaminergic drug administration. J Neurosci 29:1538-1543

Dahlin E, Neely AS, Larsson A, Backman L, Nyberg L (2008) Transfer of learning after updating training mediated by the striatum. Science 320:1510-1512

Dalley JW, Fryer TD, Brichard L, Robinson ES, Theobald DE, Laane K, Pena Y, Murphy ER, Shah Y, Probst K, Abakumova I, Aigbirhio FI, Richards HK, Hong Y, Baron JC, Everitt BJ, Robbins TW (2007) Nucleus accumbens D2/3 receptors predict trait impulsivity and cocaine reinforcement. Science 315:12671270

Daneman M, Carpenter PA (1980) Individual-differences in working memory and reading. J Verbal Learn Verbal Behav 19:450-466

Daw ND, Niv Y, Dayan P (2005) Uncertainty-based competition between prefrontal and dorsolateral striatal systems for behavioral control. Nat Neurosci 8:1704-1711

Deleu D, Northway MG, Hanssens Y (2002) Clinical pharmacokinetic and pharmacodynamic properties of drugs used in the treatment of Parkinson's disease. Clin Pharmacokinet 41:261-309

Derrfuss J, Brass M, Neumann J, von Cramon DY (2005) Involvement of the inferior frontal junction in cognitive control: metaanalyses of switching and Stroop studies. Hum Brain Mapp 25:22-34

Dodds CM, Muller U, Clark L, van Loon A, Cools R, Robbins TW (2008) Methylphenidate has differential effects on blood oxygenation level-dependent signal related to cognitive subprocesses of reversal learning. J Neurosci 28:5976-5982

Dodds CM, Clark L, Dove A, Regenthal R, Baumann F, Bullmore E, Robbins TW, Muller U (2009) The dopamine D2 receptor antagonist sulpiride modulates striatal BOLD signal during the manipulation of information in working memory. Psychopharmacology (Berl) 207:35-45

Durstewitz D, Seamans JK (2008) The dual-state theory of prefrontal cortex dopamine function with relevance to catechol-Omethyltransferase genotypes and schizophrenia. Biol Psychiatry 64:739-749

Feldman RS, Meyer JS, Quenzer LF (1997) Principles of neuropsychopharmacology. Sinauer Associates, Sunderland

Fitzgerald P, Dinan TG (2008) Prolactin and dopamine: what is the connection? A review article. J Psychopharmacol 22:12-19

Floresco SB, Jentsch JD (2011) Pharmacological enhancement of memory and executive functioning in laboratory animals. Neuropsychopharmacology 36:227-250

Floresco SB, Magyar O (2006) Mesocortical dopamine modulation of executive functions: beyond working memory. Psychopharmacology (Berl) 188:567-585

Floresco SB, Magyar O, Ghods-Sharifi S, Vexelman C, Tse MT (2006) Multiple dopamine receptor subtypes in the medial prefrontal cortex of the rat regulate set-shifting. Neuropsychopharmacology 31:297309

Frank MJ, Fossella JA (2011) Neurogenetics and pharmacology of learning, motivation, and cognition. Neuropsychopharmacology $36: 133-152$

Frank MJ, O'Reilly RC (2006) A mechanistic account of striatal dopamine function in human cognition: psychopharmacological 
studies with cabergoline and haloperidol. Behav Neurosci 120:497-517

Frank MJ, Loughry B, O’Reilly RC (2001) Interactions between frontal cortex and basal ganglia in working memory: a computational model. Cogn Affect Behav Neurosci 1:137-160

Fuke S, Suo S, Takahashi N, Koike H, Sasagawa N, Ishiura S (2001) The VNTR polymorphism of the human dopamine transporter (DAT1) gene affects gene expression. Pharmacogenomics J $1: 152-156$

Gibbs SE, D'Esposito M (2005a) A functional MRI study of the effects of bromocriptine, a dopamine receptor agonist, on component processes of working memory. Psychopharmacology (Berl) 180:644-653

Gibbs SE, D'Esposito M (2005b) Individual capacity differences predict working memory performance and prefrontal activity following dopamine receptor stimulation. Cogn Affect Behav Neurosci 5:212-221

Grant DA, Berg EA (1948) A behavioral analysis of degree of reinforcement and ease of shifting to new responses in a Weigltype card-sorting problem. J Exp Psychol 38:404-411

Haluk DM, Floresco SB (2009) Ventral striatal dopamine modulation of different forms of behavioral flexibility. Neuropsychopharmacology 34:2041-2052

Hazy TE, Frank MJ, O'Reilly RC (2006) Banishing the homunculus: making working memory work. Neuroscience 139:105-118

Heinz A, Goldman D, Jones DW, Palmour R, Hommer D, Gorey JG, Lee KS, Linnoila M, Weinberger DR (2000) Genotype influences in vivo dopamine transporter availability in human striatum. Neuropsychopharmacology 22:133-139

Hurd YL, Suzuki M, Sedvall GC (2001) D1 and D2 dopamine receptor mRNA expression in whole hemisphere sections of the human brain. J Chem Neuroanat 22:127-137

Kellendonk C, Simpson EH, Polan HJ, Malleret G, Vronskaya S, Winiger V, Moore H, Kandel ER (2006) Transient and selective overexpression of dopamine D2 receptors in the striatum causes persistent abnormalities in prefrontal cortex functioning. Neuron 49:603-615

Kimberg DY, D'Esposito M, Farah MJ (1997) Effects of bromocriptine on human subjects depend on working memory capacity. Neuroreport 8:3581-3585

Leber AB, Turk-Browne NB, Chun MM (2008) Neural predictors of moment-to-moment fluctuations in cognitive flexibility. Proc Natl Acad Sci U S A 105:13592-13597

Lewis SJ, Dove A, Robbins TW, Barker RA, Owen AM (2004) Striatal contributions to working memory: a functional magnetic resonance imaging study in humans. Eur J Neurosci 19:755-760

Luciana M, Collins P (1997) Dopaminergic modulation of working memory for spatial but not object cues in normal volunteers. J Cogn Neurosci 9:330-347

Luciana M, Depue RA, Arbisi P, Leon A (1992) Facilitation of working memory in humans by a D2 dopamine receptor agonist. J Cogn Neurosci 4:58-68

Lyon M, Robbins TW (1975) The action of central nervous system drugs: a general theory concerning amphetamine effects. In: Essman W (ed) Current developments in psychopharmacology. Spectrum, New York, pp 80-163

Marklund P, Larsson A, Elgh E, Linder J, Riklund KA, Forsgren L, Nyberg L (2009) Temporal dynamics of basal ganglia underrecruitment in Parkinson's disease: transient caudate abnormalities during updating of working memory. Brain 132:336-346

Mattay VS, Callicott JH, Bertolino A, Heaton I, Frank JA, Coppola R, Berman KF, Goldberg TE, Weinberger DR (2000) Effects of dextroamphetamine on cognitive performance and cortical activation. Neuroimage 12:268-275

Mattay VS, Goldberg TE, Fera F, Hariri AR, Tessitore A, Egan MF, Kolachana B, Callicott JH, Weinberger DR (2003) Catechol O- methyltransferase val158-met genotype and individual variation in the brain response to amphetamine. Proc Natl Acad Sci USA 100:6186-6191

McNab F, Klingberg T (2008) Prefrontal cortex and basal ganglia control access to working memory. Nat Neurosci 11:103-107

Mehta MA, Sahakian BJ, McKenna PJ, Robbins TW (1999) Systemic sulpiride in young adult volunteers simulates the profile of cognitive deficits in Parkinson's disease. Psychopharmacology (Berl) 146:162-174

Mehta MA, Swainson R, Ogilvie AD, Sahakian BJ, Robbins TW (2001) Improved short-term spatial memory but impaired reversal learning following the dopamine D2 agonist bromocriptine in human volunteers. Psychopharmacology 159:10-20

Mehta M, McGowan S, Lawrence A, Aitken M, Montgomery A, Grasby P (2003) Systemic sulpiride modulates striatal blood flow: relationships to spatial working memory and planning. Neuroimage 20:1982-1994

Mehta MA, Manes FF, Magnolfi G, Sahakian BJ, Robbins TW (2004) Impaired set-shifting and dissociable effects on tests of spatial working memory following the dopamine D2 receptor antagonist sulpiride in human volunteers. Psychopharmacology (Berl) 176:331-342

Mehta MA, Montgomery AJ, Kitamura Y, Grasby PM (2008) Dopamine D2 receptor occupancy levels of acute sulpiride challenges that produce working memory and learning impairments in healthy volunteers. Psychopharmacology (Berl) 196:157-165

Mill J, Asherson P, Browes C, D'Souza U, Craig I (2002) Expression of the dopamine transporter gene is regulated by the $3^{\prime}$ UTR VNTR: Evidence from brain and lymphocytes using quantitative RT-PCR. Am J Med Genet 114:975-979

Monsell S (2003) Task switching. Trends Cogn Sci 7:134-140

Oades RD (1985) The role of noradrenaline in tuning and dopamine in switching between signals in the CNS. Neurosci Biobehav Rev 9:261-282

Patton JH, Stanford MS, Barratt ES (1995) Factor structure of the Barratt impulsiveness scale. J Clin Psychol 51:768-774

Redgrave P, Prescott TJ, Gurney K (1999) The basal ganglia: a vertebrate solution to the selection problem? Neuroscience 89:1009-1023

Rogers RD, Monsell S (1995) Costs of a predictable switch between simple cognitive tasks. J Exp Psychol Gen 124:207-231

Sakai K (2008) Task set and prefrontal cortex. Annu Rev Neurosci $31: 219-245$

Salthouse TA, Babcock RL, Shaw RJ (1991) Effects of adult age on structural and operational capacities in working memory. Psychol Aging 6:118-127

Schmand B, Bakker D, Saan R, Louman J (1991) The Dutch Reading Test for Adults: a measure of premorbid intelligence level. Tijdschr Gerontol Geriatr 22:15-19

Schultz W (2002) Getting formal with dopamine and reward. Neuron $36: 241-263$

Seamans JK, Yang CR (2004) The principal features and mechanisms of dopamine modulation in the prefrontal cortex. Prog Neurobiol 74:1-58

Sheehan DV, Lecrubier Y, Sheehan KH, Amorim P, Janavs J, Weiller E, Hergueta T, Baker R, Dunbar GC (1998) The MiniInternational Neuropsychiatric Interview (M.I.N.I.): the development and validation of a structured diagnostic psychiatric interview for DSM-IV and ICD-10. J Clin Psychiatry 59(Suppl 20):22-33, quiz 34-57

Spielberger CD, Gorsuch RL, Lushene RE (1970) Manual for the state-trait anxiety inventory. Consulting Psychologists, Palo Alto

Stelzel C, Basten U, Montag C, Reuter M, Fiebach CJ (2010) Frontostriatal involvement in task switching depends on genetic differences in $\mathrm{d} 2$ receptor density. J Neurosci 30:14205-14212 
van Dyck CH, Malison RT, Jacobsen LK, Seibyl JP, Staley JK, Laruelle M, Baldwin RM, Innis RB, Gelernter J (2005) Increased dopamine transporter availability associated with the 9-repeat allele of the SLC6A3 gene. J Nucl Med 46:745-751

VanNess SH, Owens MJ, Kilts CD (2005) The variable number of tandem repeats element in DAT1 regulates in vitro dopamine transporter density. BMC Genet 6:55 van Schouwenburg MR, den Ouden HE, Cools R (2010) The human basal ganglia modulate frontal-posterior connectivity during attention shifting. J Neurosci 30:9910-9918

Willeit M, Praschak-Rieder N (2010) Imaging the effects of genetic polymorphisms on radioligand binding in the living human brain: a review on genetic neuroreceptor imaging of monoaminergic systems in psychiatry. Neuroimage 53:878-892 